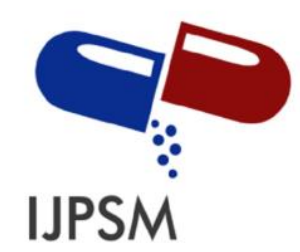

Divyanshu Sharma et al, Int. Journal of Pharmaceutical Sciences and Medicine (IJPSM),

Vol.6 Issue. 9, September- 2021, pg. 27-33

ISSN: 2519-9889

Impact Factor: 3.426

\title{
SPECTROPHOTOMETRIC METHOD DEVELOPMENT AND VALIDATION FOR SIMULTANEOUS ESTIMATION OF ABACAVIR AND LAMIVUDINE IN COMBINED DOSAGE FORM
}

\author{
Divyanshu Sharma $^{1}$; Prerna Chaturvedi ${ }^{2}$ \\ Swami Vivekanand College of Pharmacy, Khandwa Road, Indore, (M.P.), INDIA
}

DOI: 10.47760/ijpsm.2021.v06i09.004

\begin{abstract}
Antiretroviral therapy [ART] has been developed remarkably within last three decades, since the first NRTI (nucleoside reverse transcriptase inhibitor) developed. For the mostly patients the challenge of complete and sustain suppression of viral has been clarify, since the triple therapy arrived. Convenient pill burden and tolerability are the main limiting factor for enhancing the long term benefit of ART. ABACAVIR (ABA) and LAMIVUDINE (LAM) are synthetic nucleotide analog (SNA) that showing a synergistic and potent inhibitory effect on human immunodeficiency virus-I (HIV-I), causative agent of AIDS. ABA and LAM belongs to nucleoside reverse transcriptase inhibitor (NRTI) class. As per new therapeutic strategy these two antiretroviral (ARV) drugs are required for the treatment of AIDS. When ARV regimens changed due to lack to virologic response ABA should be avoided. ABA is getting converted in to the active metabolite (carbovir triphosphate) which is an deoxyguanosine-5' triphosphate analog by intracellular enzymes. LAM gets converted in its active 5'-triphosphate metabolite through phosphorylation. Chemically, ABA is (1S, cis)-4-[2-amino-6-(cyclopropyl amino)-9H-purin-9-yl]-2cyclopentene-1-methanol sulphate and LAM is (2R, cis)-4-amino-1-(2-hydroxymethyl-1, 3oxathiolan-5-yl)-(1H)-pyrimidin-2-one. Fig. 1 and 2 show ABA and LAM's structure respectively.
\end{abstract}

KEYWORDS: Simultaneous estimation, Abacavir, lamivudine, spectroscopy.

\section{INTRODUCTION}

In Multi drug formulations, the presence of two or more drugs can leads to interference, they interfere with each other during their estimation. Many techniques had applied for simultaneous estimation of such multi drug formulations, they are follows-

- Simultaneous equation method.

- Area under curve method.

- Absorption ratio method.

- Derivative spectroscopy method.

- Chemical derivatization method.

- Multi Component mode of analysis. 


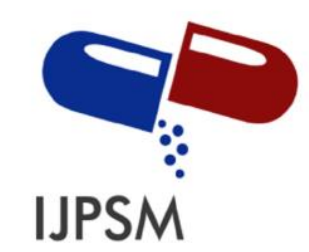

Divyanshu Sharma et al, Int. Journal of Pharmaceutical Sciences and Medicine (IJPSM),

Vol.6 Issue. 9, September- 2021, pg. 27-33

ISSN: 2519-9889

Impact Factor: 3.426

\section{SIMULTANEOUS EQUATION METHOD}

If a sample containing two drugs ( $\mathrm{X}$ and $\mathrm{Y}$ ) each of them give absorbance on $\lambda_{\max }$ of each other's. the actual quantity of both drugs can be determined by simultaneous estimation method (vierodt's method).

Criteria for getting maximum precision is only when the $\lambda_{\max }$ of the two drugs is rationally dissimilar. The other criteria comprise that two drugs do not interact chemically.

\section{AREA UNDER CURVE METHOD}

The area under curve method is suitable when there are broad spectra or no sharp peak obtained. It consists of the calculation of unified value of absorbance with respect to two selected wavelengths $\lambda_{1}$ and $\lambda_{2}$. The horizontal axis is selected by entering the wavelength range over which area has to be determined. In combined drugs $\lambda_{1}$ and $\lambda_{2}$ stands for the wavelengths of the components. To get the actual concentration of the both drugs the unified value of absorbance in the wavelength range of both the drugs are substituted in the simultaneous equation.

$$
C_{x}=\frac{A_{2} a_{y 1}-A_{1} a_{y 2}}{a_{x 2} a_{y 1}-a_{x 1} a_{y 2}} \quad \text { And } \quad C_{x}=\frac{A_{1} a_{x 2}-A_{2} a_{x 1}}{a_{x 2} a_{y 1}-a_{x 1} a_{y 2}}
$$

\section{DERIVATIVE SPECTROPHOTOMETRIC METHOD}

Derivative spectrophotometric method consists of the transformation of general spectrum to first, second or higher derivative spectrum. The transformation occurs in derivative are known by reference to a Gaussian band which speaks for an optimal absorption band.

A first-order derivative is a plot of the gradient of the absorption curve ( rate of change of the absorbance with wavelength, $\mathrm{dA} / \mathrm{d} \lambda$ ) against wavelength.

A Second-order derivative spectrum is a plot of the curve of the absorption spectrum against wavelength $\left(\mathrm{d}^{2} \mathrm{~A} / \mathrm{d} \lambda^{2}\right)$. The second derivative at any wavelength $(\lambda)$ is related to concentration by the following equations:

$$
\frac{d^{2 A}}{d \lambda^{2}}=\frac{d^{2} A_{1}^{1} \text { percent }}{d \lambda^{2}} \times \frac{c^{\prime} b}{10}=\frac{d^{2} A \varepsilon}{d \lambda^{2}} \times \frac{c b}{10}
$$

\section{DRUG PROFILE}

Abacavir (Fig. no. 01) is a NRT (nucleoside reverse transcriptase) Inhibitor with activity as a HIV antiretroviral agent and is a nucleoside analogue. In terms of structure it is differ from another reverse transcriptase inhibitor like didanosine, lamivudine, stavudine, zalcitabine, zidovudine. 


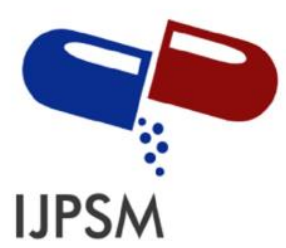

Divyanshu Sharma et al, Int. Journal of Pharmaceutical Sciences and Medicine (IJPSM),

Vol.6 Issue. 9, September- 2021, pg. 27-33

ISSN: 2519-9889

Impact Factor: 3.426

It belongs to the category of a carboxylic nucleosides analogue instead of a dideoxynucleoside analogue. It's converted by intracellular enzymes to the carbovir triphosphate, active metabolites. It's a poor inhibitor of cellular deoxyribonucleic acid (DNA) polymerases $\alpha, \beta$ and $\gamma$.

After oral administration of abacavir sulphate is rapidly absorbed and it's distributed extensively. An absolute bioavailability of abacavir sulphate is $\sim 83 \%$, which isn't suffering from food. Abacavir was approved by FDA in December 1998.

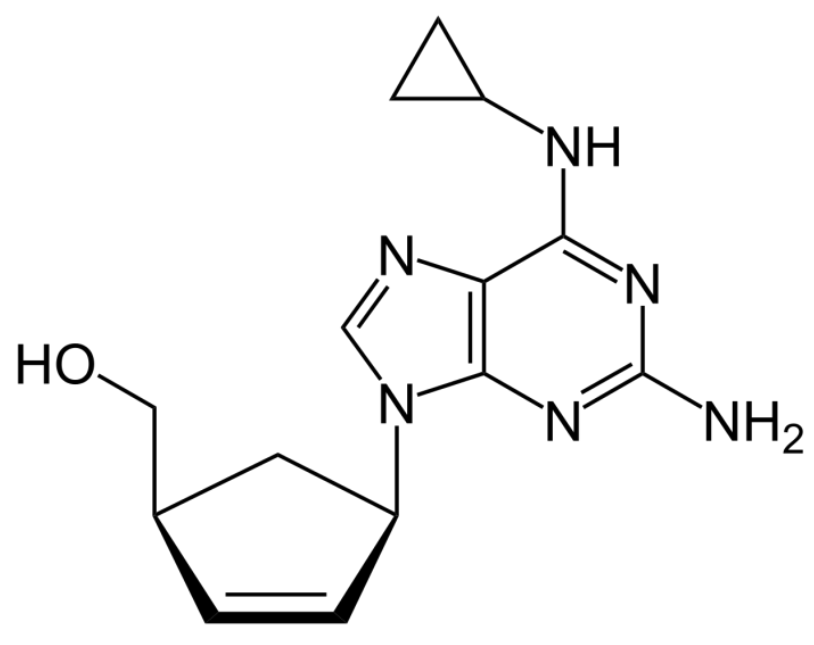

Fig. no. 01

Lamivudine (Fig.no. 02) is a drug in the same category of nucleoside reverse transcriptase inhibitor as abacavir. Lamivudine administered orally, it is rapidly absorbed with a bioavailability of $80 \%$ to $87 \%$.

FDA approval granted in 1995 for lamivudine to use pediatric and adult based on increase in CD4 T-lymphocytes count on a regimen of zidovudine and lamivudine compared with either zalcitabin and zidovudine combination or drug alone was initial approval. Lamivudine is also used to treat hepatitis B when chronic and other options are impossible. 


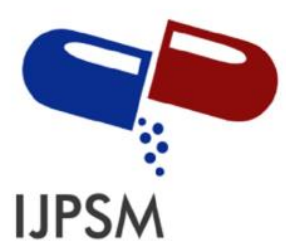

Divyanshu Sharma et al, Int. Journal of Pharmaceutical Sciences and Medicine (IJPSM),

Vol.6 Issue. 9, September- 2021, pg. 27-33

ISSN: 2519-9889

Impact Factor: 3.426

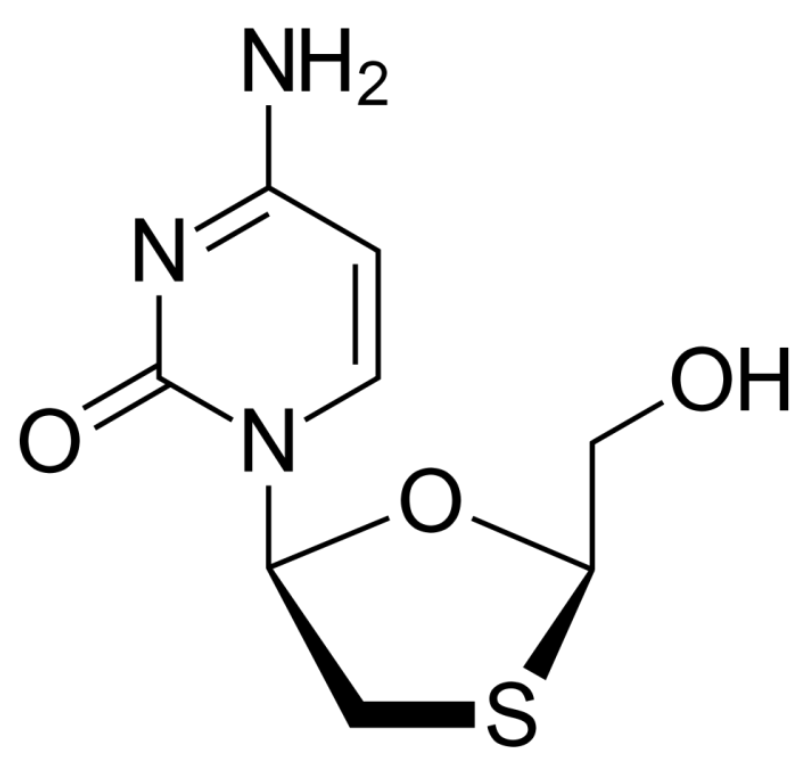

Fig. no. 02

\section{SIDE EFFECTS OF LAMIVUDINE AND ABACAVIR}

Abacavir and lamivudine combination affects your immune system (directly or indirectly) because of this, certain side effects may occur (even weeks or months after administration). They are follows:-

- Symptoms of new infection: - swollen glands, fever, cold sores, diarrhea, night sweats, cough wheezing and weight loss;

- Difficult swallowing or speaking:- trouble in eye movement and balance, prickly feeling or weakness; or

- Enlarged thyroid (swelling in throat or neck), menstrual changes.

Some common side effects are:-

- Allergic reaction;

- Disturbed sleep, depression;

- Feeling tired or week;

- Dizziness, headache, migraine; or

- Diarrhea or nausea. 


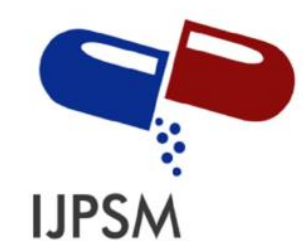

Divyanshu Sharma et al, Int. Journal of Pharmaceutical Sciences and Medicine (IJPSM),

Vol.6 Issue. 9, September- 2021, pg. 27-33

ISSN: 2519-9889

Impact Factor: 3.426

\section{DOSING}

\section{FOR PEDIATRIC PATIENTS}

\begin{tabular}{|c|c|c|c|}
\hline \multirow[t]{2}{*}{ Weight } & \multicolumn{2}{|c|}{$\begin{array}{l}\text { Dosage regimen abacavir sulphate }(60 \mathrm{mg}) \text { and lamivudine } \\
(30 \mathrm{mg}) \text { tablets }\end{array}$} & \multirow[t]{2}{*}{$\begin{array}{l}\text { Total Daily } \\
\text { Dose(A/L)mg }\end{array}$} \\
\hline & AM Dose (mg A/ mg L) & PM Dose (mg A/ mg L) & \\
\hline $5 \mathrm{~kg}$ & $1 / 2$ tablet $(30 \mathrm{~A} / 15 \mathrm{~L})$ & 1 tablet $(60 \mathrm{~A} / 30 \mathrm{~L})$ & $90 / 45$ \\
\hline $6-9 \mathrm{~kg}$ & 1 tablet $(60 \mathrm{~A} / 30 \mathrm{~L})$ & 1 tablet $(60 \mathrm{~A} / 30 \mathrm{~L})$ & $120 / 60$ \\
\hline $9-12 \mathrm{~kg}$ & 1.5 tablet $(90 \mathrm{~A} / 45 \mathrm{~L})$ & 1.5 tablet $(90 \mathrm{~A} / 45 \mathrm{~L})$ & $180 / 90$ \\
\hline $12-17 \mathrm{~kg}$ & 2 tablet $(120 \mathrm{~A} / 60 \mathrm{~L})$ & 2 tablet $(120 \mathrm{~A} / 60 \mathrm{~L})$ & $240 / 120$ \\
\hline $17-20 \mathrm{~kg}$ & 2.5 tablet $(150 \mathrm{~A} / 75 \mathrm{~L})$ & 2.5 tablet $(150 \mathrm{~A} / 75 \mathrm{~L})$ & $300 / 150$ \\
\hline $20-25 \mathrm{~kg}$ & 3 tablet $(180 \mathrm{~A} / 90 \mathrm{~L})$ & 3 tablet $(180 \mathrm{~A} / 90 \mathrm{~L})$ & $360 / 180$ \\
\hline $25-29 \mathrm{~kg}$ & 3.5 tablet $(210 \mathrm{~A} / 105 \mathrm{~L})$ & 3.5 tablet $(210 \mathrm{~A} / 105 \mathrm{~L})$ & $420 / 210$ \\
\hline $29-35 \mathrm{~kg}$ & 4 tablet $(240 \mathrm{~A} / 120 \mathrm{~L})$ & 4 tablet $(240 \mathrm{~A} / 120 \mathrm{~L})$ & $480 / 240$ \\
\hline$\geq 35 \mathrm{~kg}$ & 5 tablet $(300 \mathrm{~A} / 150 \mathrm{~L})$ & 5 tablet $(300 \mathrm{~A} / 150 \mathrm{~L})$ & $600 / 300$ \\
\hline
\end{tabular}

$\mathrm{A}=$ abacavir sulfate; $\mathrm{L}=$ lamivudine

\section{FOR ADULT PATIENTS}

The recommended dosage of abacavir is $600 \mathrm{mg}$ and for lamivudine it is $300 \mathrm{mg}$ taken orally daily, in combination with other antiretroviral agents, with or without food.

\section{MODE OF ACTION}

\section{ABACAVIR}

Abacavir is a nucleoside reverse trancriptase inhibitor that inhibits viral replication. It is guanosine analogue that is phosphorylated to carbovir triphosphate (CBV-TP). CBV-PT competes with the viral molecules and is incorporated into the viral DNA. CBV-TP is integrated into the viral DNA, transcription and HIV reverse transcriptase is inhibited.

\section{LAMIVUDINE}

Lamivudine is synthetic nucleoside analogue, intracellularly lamivudine is phosphorylated to its triphosphate metabolite, lamivudine triphosphate (UTC-TP). The principal mode of action of UTC-TP is the 


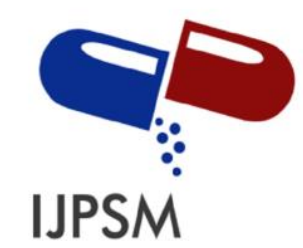

Divyanshu Sharma et al, Int. Journal of Pharmaceutical Sciences and Medicine (IJPSM),

Vol.6 Issue. 9, September- 2021, pg. 27-33

ISSN: 2519-9889

Impact Factor: 3.426

inhibition of HIV-1 reverse transcriptase via DNA chain termination after incorporation of the nucleotide analogue into viral DNA.

\section{PRINCIPAL OF UV SPECTROSCOPY}

UV spectroscopy obeys the Beer-Lambert law, which states that: when a beam of monochromatic light is passed through a solution of an absorbing substance, the rate of decreased of intensity of radiation with thickness of the absorbing solution is proportional to the incident radiation as well as the concentration of the solution.

The expression of Beer-Lambert law is-

$$
A=\log \left(I_{0} / I\right)=E c l
$$

Where,

$$
\begin{aligned}
& A=\text { absorbance } \\
& I_{0}=\text { intensity of light incident upon sample cell } \\
& I=\text { intensity of light leaving sample cell } \\
& \mathrm{c}=\text { molar concentration of solute } \\
& \mathrm{l}=\text { length of sample cell } \\
& \mathrm{E}=\text { molar absorptivity }
\end{aligned}
$$

From the Beer-Lambert law it is clear that greater the number of molecules capable of absorbing light of a given wavelength, the extent of light absorption. This is the basic principal of UV spectroscopy.

\section{CONCLUSION}

Abacavir and lamivudine are combined together and widely used as anti-HIV preparation. It's daily once preparation and thus its dose play a very important role. Proper analysis and estimation of these drugs is crucial and the dose related side effects could be combatted.

As it's seen from literature various techniques are now a days available for determination of abacavir and lamivudine in bulk as well as in dosage forms. Out of different methods available UV spectroscopy has gained considerable importance and is widely used.

Advances are made in these techniques to give better results with improved techniques. A brief about UV spectroscopy was given that helps 


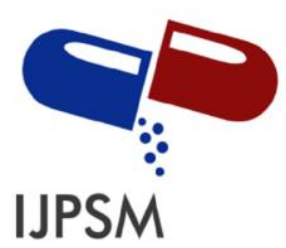

Divyanshu Sharma et al, Int. Journal of Pharmaceutical Sciences and Medicine (IJPSM),

Vol.6 Issue. 9, September- 2021, pg. 27-33

ISSN: 2519-9889

Impact Factor: 3.426

better understanding of the principals involved in the method. Future advancement in this field will help many new methods to evolve that would be economic and better for analysis of these drugs in bulk and dosage forms.

\section{REFERENCES}

[1]. Appalaraju SK, Arvind B, Kamalapurkar OS, Sarasambi S, Asian Journal of Chemistry, 14, 2002, 815-818. 2.

[2]. Mirza S, Palaskar PS, Dehghan MHG, Mokale SN, Asian Journal of Chemistry, 2(4), 2009,461.

[3]. Devmurari VP, International Journal of Pharmaceutical Sciences and Research, 1(7), 2010,

[4]. Sudha T, SaminathanJ, Kondapalli A, Manthena K, Yanamadala B,Ganesan V, Journal of Chemistry and Pharmaceutical Research,2(5),2010,45-51.

[5]. Sudha T, Ravikumar VR,Hemalatha PV, International Journal of Pharmaceutical and Biomedical Research,1(4),2010,108-13.

[6]. Sudha T, Ravikumar VR, Hemalatha PV, International Journal of Pharmaceutical Sciences and Research, 1(11), 2010, 107-11

[7]. Nagulwar V.P. and Bhusari K.P.: Development of UV Spectrophotometric Method for the Simultaneous Estimation of Abacavir and Lamivudine in Combined Tablet Dosage Form using Multicomponent Mode. Int J Pharm Sci Res, 2012; Vol. 3(7): 2159- 2162.

[8]. Deepali G., Elvis M. UV spectrophotometric method for assay of the anti-retroviral agent lamivudine in active pharmaceutical ingredient and in its tablet formulation. Pharm analysis. 2010; 2 (4):417-419.

[9]. Kapoor N., Sateesh K. and Ramesh. P. Simultaneous determination of lamivudine and stavudine in antiretroviral fixed dose combinations by first derivative spectrophotometry and high performance liquid chromatography

[10].Manikanta Kumar. A, B. Naga Sandhya*, Mahesh Nasare, V. V. L. N Prasad, Prakash V Diwan; Development and validation of UV Spectrophotometric method for simultaneous estimation of Lamivudine and Efavirenz in the Pharmaceutical Dosage Form; J. Adv. Pharm. Edu. \& Res. 2012:; 4: 210-214. 